\title{
Development of Flammability Criteria for Transformer Dielectric Fluids
}

Richard G. Gann

Center for Fire Research

National Engineering Laboratory

National Bureau of Standards

U.S. Department of Commerce

Washington, D.C. 20234

Final Report

February 1980

Issued March 1980

Prepared for:

U.S. Department of Energy

Electric Energy Systems Division

Power Delivery Branch

Washington, D.C. 20545 



\section{DEVELOPMENT OF FLAMMABILITY CRITERIA FOR TRANSFORMER DIELECTRIC FLUIDS}

Richard G. Gann

Center for Fire Research

National Engineering Laboratory

National Bureau of Standards

U.S. Department of Commerce

Washington, D.C. 20234

Final Report

February 1980

Issued March 1980

Prepared for:

U.S. Department of Energy

Electric Energy Systems Division

Power Delivery Branch

Washington, D.C. 20545

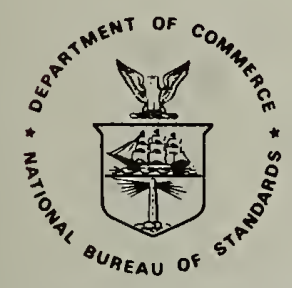

U.S. DEPARTMENT OF COMMERCE, Philip M. Klutznick, Secretary

Luther H. Hodges, Jr., Deputy Secretary

Jordan J. Baruch, Assistant Secretery for Science and Technology

NATIONAL BUREAU OF STANDARDS, Ernest Ambler, Director 

LIST OF TABLES . . . . . . . . . . . . . . . . . . . . . v

LIST OF FIGURES

Abstract . . . . . . . . . . . . . . . . . . . . 1

1. INTRODUCTION . . . . . . . . . . . . . . . . . . . 1

1.1 Background . . . . . . . . . . . . . . . . 1

1.2 Magnitude of the Problem ............... 4

1.3 Objectives of This Effort . . . . . . . . . . . . 5

2. THE CURRENT STANDARD . . . . . . . . . . . . . . . . . . . 6

3. THE SLOW LEAK SCENARIO . . . . . . . . . . . . . . . . . 7

3.1 Description of Hazard . . . . . . . . . . . . 7

3.2 Characteristics of Pool Fires . . . . . . . . . . . 8

3.2.1 Ignition . . . . . . . . . . . . . . . . 8

3.2.2 Flame Spread Over the Pool Surface... . . . . . 9

3.2.3 Ignition of Surrounding Fuels . . . . . . . . . 10

3.2.4 Dependence of Pool Burning Rate on

Prevailing Atmospheric Conditions . . . . . . . . 11

3.3 Pool Fire Performance Tests . . . . . . . . . . . . 12

3.3.1 The Factory Mutual Approval Scheme . . . . . . . 12

3.3.2 Rate of Heat Release Determinations . . . . . . . 14

3.4 Aging of Fluids . . . . . . . . . . . . . . . 15

4. THE VIOLENT RUPTURE SCENARIO . . . . . . . . . . . . . . . 17

4.1 Description of Hazard . . . . . . . . . . . . . 17

4.2 Applicability of Standard Test Methods . . . . . . . . 18

4.3 Explosion Tests . . . . . . . . . . . . . . . . 18

4.4 Model for the Ignition of Remote Fuels

by Flaming Droplets . . . . . . . . . . . . 19

5. EVALUATING ALTERNATIVE FIRE SAFETY STRATEGIES • • • • • • • • . 23

6. RECOMMENDATIONS FOR FURTHER WORK . . . . . . . . . . . . 26

6.1 Assessment of the Current Status . . . . . . . . . . 26

6.2 Needed Test Development . . . . . . . . . . . . . 26

6.2.1 Fluid Ignitability . . . . . . . . . . . . . 27

6.2.2 Radiant Ignition of Surrounding Materials . . . . . 28

6.2.3 Contact Ignition of Surrounding Materials . . . . . 28

6.2.4 Damage to the Building . . . . . . . . . . . 29

6.3 Epilogue .. . . . . . . . . . . . . . . 29 
TABLE OF CONTENTS (continued)

7. ACKNOWLEDGMENTS . . . . . . . . . . . . . 30

8. REFERENCES ............................. 31 APPENDIX A. COMPARISON OF RADIATION CHARACTERISTICS OF SILICONE AND HYDROCARBON FLUID POOL FIRES . . . . . . A-1

APPENDIX B. A RECENT CASE OF PCB LEAKAGE AND POLLUTION

from The Washington Post, September 29, 1979 . . . . B-1 
Table

1. Expected annual national losses . . . . . . . . . 34

2. Cost plus loss per transformer over transformer lifetime . 35

A-1. Long-wavelength pass filters . . . . . . . . . . . A-5

\section{LIST OF FIGURES}

Figure

1. Temperature profiles of solid-liquid system at droplet impact $(t=0)$ and at some later time $\left(t=t^{\prime}\right) . . .+. .36$

A-1. Apparatus schematic . . . . . . . . . . . . A-6 A-2(a). Photomultiplier response data from pump oil fire . . . A-7 A-2(b). Photomultiplier response data from silicone fluid fire . A-8 A-2(c). Photomultiplier response data from tungsten bulb . . . A-9 A-3(a). Spectral data from pump oil fires (intensity in arbitrary units) . . . . . . . . . . . . . A-10

A-3(b). Spectral data from silicone fluid fires (intensity in arbitrary units) . . . . . . . . . . . . . A-11

A-3(c). Spectral data from tungsten bulb fires (intensity in arbitrary units) .................. A-12 


\title{
DEVELOPMENT OF FLAMMABILITY CRITERIA \\ FOR TRANSFORMER DIELECTRIC FLUIDS
}

\author{
Richard G. Gann
}

\section{Abstract}

With the recent ban on the use of polychlorinated biphenyls, it has become necessary to examine the fire safety requirements for electrical insulating fluids. The hazards are delineated and the magnitude of the transformer fire problem assessed. The current fire code and standard test methods are shown to be inadequate. Approaches to fluid fire performance testing are presented, as is a basis for evaluating the economic impact of alternative fire safety strategies. The report concludes with recommendations for further work.

Key words: Fire; fluids; pool fires; transformers.

\section{INTRODUCTION}

\subsection{Background}

The routine availability of electrical power has become an essential facet of our life style. With the exception of an occasional shock or blown fuse, we assume total safety and reliability of the power transmission network. However, this has only evolved because each element in the system has been itself engineered to be safe and reliable. We have responded to changes in technology in the past and maintained or improved the system. Rubber cable insulation has given way to polyvinyl chloride, circuit breakers are replacing fuses, and grounded outlets are becoming commonplace. 
Due to certain recent events, we now need to reexamine one of the basic elements--the transformer. These devices convert an available input voltage to that needed by the device at hand. There are millions of indoor transformers in use, ranging from the small step-up transformers in televisions to the large step-down power transformers in apartment complexes and shopping centers.

Inside a transformer case are two coils of wire, each consisting of a number of turns wound on a single iron core. The coils are insulated from each other and from the core. Each turn is insulated from its neighbor as well. The power is transformed and transmitted as the current flow in the incoming, or primary, coil induces a current flow in the outgoing, or secondary, coil.

Ideally, the ratio of the number of turns in the two coils is also the ratio of the primary to secondary voltage. In practice, the power output of a transformer is somewhat less than the power input due to impedance heat losses in the windings and the core. While the efficiency of large transformers approaches unity, even a small heat loss poses a cooling problem. Thus an insulating, or dielectric, medium is required to also transfer heat from the source to the case. From there, energy is radiated and convected to the surroundings.

For many transformers, liquids of appropriate dielectric strength and viscosity are being used to meet the insulation and heat transfer objectives. The fluids have had admirable in-service histories. Nevertheless, they pose a potential hazard in that under sufficiently strenuous conditions, virtually all liquids will burn. Transformer fires fall into two classes, those resulting from slow fluid leaks and those resulting in violent rupture of the transformer case. The former are far more prevalent; the latter are potentially more hazardous. Nonetheless, fires of either origin can ruin the transformer, delay the return of electrical service, damage the room or building, and injure or kill occupants or firefighters. Thus, a third constraint is placed 
on the transformer, and specifically the fluid--it must operate within an acceptable degree of fire risk.

Heretofore, two classes of fluids, mineral oils and polychlorinated biphenyls, have found wide usage. The former are the more prevalent. These petroleum distillate fractions are relatively inexpensive and meet conventional electrical and environmental requirements, at least to the extent the latter have been formulated. Since they are deemed to present an unacceptable flammability hazard, their use is constrained by the National Electrical Code $[1]^{1}$ to outdoor transformers or indoor units enclosed in a fire resistant vault. By contrast, the polychlorinated biphenyls, also referred to as PCBs or askarels, not only have excellent electrical properties, but have also been considered nonflammable. Thus they represent the dielectric of choice in a large number of indoor uses where their high cost is more than offset by the savings in the cost of supplemental fire protection. However, over the past decade, evidence has accumulated that these compounds present a significant biological hazard. They are thus considered unacceptable for manufacture and use.

Industry has not been idle during this dilemma. A variety of candidate substitute fluids have been developed to "replace" the PCBs. These fall into three classes: high performance hydrocarbons, polydimethylsiloxane (silicone), and chlorinated aromatics. However, no operational fire safety criteria had been developed. As a result, we are now faced with a desire to use a substitute fluid for askarels without having a basis to determine acceptability.

\footnotetext{
Numbers in brackets refer to the literature references 1 isted at the end of this report.
} 


\subsection{Magnitude of the Problem}

Our prime source of fire data is the National Fire Incident Reporting System (NFIRS) which is operated by the U.S. Fire Administration [2]. In a survey of their data for 1976, 1977 and early 1978, including nearly one million fires in the data base and elght states reporting, 209 cases involved indoor transformers. Four of these fires resulted in an injury, none in any deaths. A more recent sampling of 1978 fires revealed that in a data base of about 230,000 fires, only seven began with indoor transformers. There were no injuries or deaths. The maximum reported damage in these seven fires was $\$ 2000$.

The difference between the two data sets is due to the small number of incidents. Generally injuries and deaths in this type of fire correlate with the fire spreading beyond the room of origin. Once a fire spreads outside the room, it is unimportant how it started. Thus it is fair to use the number of transformer fires that spread beyond the room of origin, the total number of fires that did so, and the total number of resulting injuries and deaths to estimate a total annual transformer fire picture for the nation. With this approach, and using the 1976-78 NFIRS data, we calculate there are about 6000 indoor transformer fires per year, resulting in about 300 injuries and seven deaths, as well as 40 million dollars of damage. These are extrapolated figures, and it should especially be noted that no fire deaths appear in the raw data.

To help put this in perspective, we experience some three million reported fires per year (30 million unreported), and the average death rate is about three per thousand fires [3]. The numbers here are 6000 fires and about one death per thousand fires. Clearly product quality and current codes and practices have resulted in a quite low fire-loss profile. The question we now address is: With askarels removed, can a (similarly) reasonable degree of fire safety be achieved with replacement fluids? 
In 1975, the Energy Research and Development Administration (ERDA) requested the National Bureau of Standards to appraise the existing flammability test methodology relevant to transformer fluids standards and to elucidate the test-related research and development need to evaluate new fluids. The final report on that project [4] noted that while there were several standard flammability tests for fluids, they are not sufficient to evaluate in-use performance. It was thus recommended that research be directed at developing flammability performance criteria. The authors also recommended the development of tests that would be a realistic indicator of fire hazard.

Following that report, ERDA (now DOE) then requested the NBS Center for Fire Research to proceed toward a comprehensive evaluation of recommendations for test procedures for transformer fluid flammability. During this project, we have performed in-house research, funded extramural research, and worked with other active committees and organizations. Specific areas of effort have included:

1. Accumulation and evaluation of fire incidence data.

2. Detailing of the fire scenarios and the resulting fire hazard.

3. Development of performance tests for the slow leak scenario.

4. Establishment of the radiation characteristics of fires of different fluids.

5. Development of test concepts for future study of the violent rupture scenario.

6. Model for Ignition of other materials by flaming fluid droplets (violent rupture scenario).

7. Formalism for evaluating the relative merits of various fire protection alternatives.

8. Development of an approach for evaluating the effect of electrical aging on fluid flammability. 
The remainder of this report is a description of the current status of fluid flammability evaluation and test methods with details of the NBS-CFR effort. Much supplementary background material is contained in a prior report [4] which should be considered prerequisite reading. In addressing the problem, we have confined ourselves to indoor transformers. In the conclusion are recommendations for extension of the current work and identification of further needs.

\section{THE CURRENT STANDARD}

The National Electrical Code [1] is the reference used by local officials as a basis for approval of a transformer installation. This is a frequently changing document, with further revisions under consideration now. Regarding indoor, liquid-filled transformers, the most recent (1978) version reads as follows:

"450-23. High Fire Point Liquid-Insulated Transformers. Transformers insulated with a nonpropagating liquid approved for the purpose, having a fire point not less than $300^{\circ} \mathrm{C}$, shall be permitted to be installed indoors or outdoors. Such transformers installed indoors and rated over 35,000 volts shall be installed in a vault.

For the purposes of this article, a nonpropagating liquid shall be one which, when subjected to a source of ignition, may burn but the flame will not spread from the source of ignition.

450-24. Askare1-Insulated Transformers Installed Indoors. Askare1insulated transformers installed indoors and rated over $25 \mathrm{kVA}$ shall be furnished with a pressure-relief vent. When installed in a poorly ventilated place, they shall be furnished with a means for absorbing any gases generated by arcing inside the case, or the pressure-relief vent shall be connected to a chimney or flue that will carry such gases outside the building. Askarel-insulated transformers rated over 35,000 volts shall be installed in a vault.

450-25. 011-Insulated Transformers Installed Indoors. 011-insulated transformers installed indoors shall be installed in a vault constructed as specified in Part $C$ of this article. 
Exception No. 2: Where the voltage does not exceed 600, a vault shall not be required if suitable arrangements are made to prevent a transformer oil fire from igniting other materials; and the total capacity in one location does not exceed $10 \mathrm{kVA}$ in a section of the building classified as combustible, or $75 \mathrm{kVA}$ where the surrounding structure is classified as fire-resistant construction."

From the viewpoint of the consumer this is a simple procedure to follow. Either the fluid supplier certifies certain properties and test results or the transformer must be contained in a vault. A typical vault with 3-hour fire resistance is of 6-inch thick reinforced concrete. It is thus expensive, bulky and heavy. It is certain to force design perturbations in a new construction and be most difficult to incorporate when retrofitting transformers.

To be excepted from vault containment, the transformer must be under $35 \mathrm{kV}$ and filled with one of the pending PCB substitutes. This in itself poses two problems. The first is that no test method or geometry is defined to establish the fluid as non propagating. Pool tests of one geometry will give different results from another geometry. All are likely to differ from a spray test. "Non propagating" is too absolute a term; virtually all fluids can be made to undergo flame spread under sufficiently severe conditions. The second difficulty is the phrase "approved for the purpose." There is no definition of the source(s) of authoritative approval. Thus, from the viewpoint of the supplier's liability, this is an untenable situation. To alleviate this, we must define the fire hazards, quantify the risks, devise appropriate test methods, verify their applicability, and identify and obtain recognition from an appropriate organization.

\section{THE SLOW LEAK SCENARIO}

\subsection{Description of Hazard}

The sequence of events below generally results from external damage to the transformer case. This may be due to a flaw in manufacture, 
rough handling, perforation by a fork-lift truck, etc. The dielectric fluid drains from the case, forming a puddle on the floor. Escaped fluid can then be ignited by a remote source as the fluid flows to it, or contained fluid can be ignited by the now overheated transformer core. The result is a flaming pool of liquid which may or may not be physically bounded. For reasons which will become obvious soon, we will deal with bounded pools in this section and the unbounded case In section 4. Even when the fluid 1tself is confined, the radiation from the flames can pyrolyze and ignite remote fuel, while the radiative and convective heat weakens the structural strength of the room or building. Thus, the fire phenomena of concern are ignitability, flame spread across the pool surface, and heat release rate.

\subsection{Characteristics of Pool Fires}

More than one hundred papers have been published on the burning behavior of bounded liquids, 1.e., pool fires. Beginning in the post-World War II era, the modern effort continues with the classic, comprehensive study of Blinov and Khudiakov [5] and a fine review paper by $\mathrm{Ha} 11$ [6].

\subsubsection{Ignition}

The minimum temperature at which a fuel bursts into flames depends on whether the stimulus is merely thermal or also includes a discrete free radical source such as a flame, arc or spark. In the former case, this is referred to as the autolgnition temperature. In the latter, the pertinent temperatures are the flash point, at which the first flames appear, and the fire point, a slightly higher temperature at which the flames are sustained. The lowest of the three is the flash point, the temperature at which the lean flammability limit is reached in the vapor above the liquid. The fire point is slightly higher since the flames must feed back enough energy to the liquid surface to vaporize more fuel and maintain at least a lean limit mixture in the vapor phase. The 
autolgnition temperature is much higher. Since no pilot is present with a source of free radicals, the gases must be hot enough for thermal breakdown of the fuel to free radicals to occur or for the rate of fuel-oxygen reaction to be fast enough for oxidative pyrolysis of the fuel.

The standard test methods to determine these temperatures are described in the previous NBS report. (No new tests have appeared in the interim.) Small cups of fuel are used in a nominally isothermal apparatus. An actual fuel spill is far from this. Most likely the initial pool temperature will approach ambient. Since the fluid has a finite thermal conductivity and a significant viscosity, an ignition source applied at one end of the pool may raise the temperature locally. Heat losses to the rest of the pool and to the floor could well balance the heat input at a temperature below the fire point, thus preventing a sustained ignition. Clearly, then, it is not sufficient to know the fire point of the fluid; one must also know its thermal properties and those of the surroundings. To be sure, a fire point of $1000^{\circ} \mathrm{C}$ could be required and would undoubtedly reduce the pool fire damages to nearly zero. However, this criterion would not be met by any currently known fluid of appropriate electrical properties. The current $300^{\circ} \mathrm{C}$ minimum fire point required by the National Electrical Code is a compromise value, imposing a burden on the ignition source to substantially heat the fluid yet keeping within the constraints of industrial capability, fluid cost, and transformer compatibility. The value is not unreasonable from a safety record viewpoint. However, it still remains for us to ascertain the necessity of so high a value.

\subsubsection{Flame Spread Over the Pool Surface}

The magnitude of the heat release rate and the longevity of the fire itself will be in large part determined by the rate at which the flames engulf the entire fuel surface. In assessing this process, much the same points are involved as in the previous section. Once the initial, 
localized flame is established, both subsurface convection [7] and flame plume radiation [8] heat the adjacent fluid. When the surface temperature reaches the fire point for a given incremental area, the vapor above it is ignited by the adjacent flame and the plume expands to cover this new area as well. This will continue until the full surface is involved or (rarely) until some location is reached where the heat losses to the surroundings exceed the incident energy. The rate of flame spread will depend on fluid properties (thermal conductivity, viscosity), flame characteristics (height, breadth, opacity), pool container properties (surface area, aspect ratio, container thermal conductivity), pool properties (pool depth, lip height above fluid), and surroundings (degree and geometry of confinement, thermal conduction losses and radiative reinforcement).

At present there is no standard test method for flame spread over liquids. Even if there were, with this complexity of variables, its applicability to any given situation would be fortuitous. Fortunately, for the fluids currently involved here and the geometries under consideration (see section 3.3), the flame spread time to cover the entire fuel surface is well under the total burning time even for fairly shallow pools $(\sim 5 \mathrm{~cm})$. Thus, in this scenario, the rate of flame spread upon sustained ignition is a secondary issue.

\subsubsection{Ignition of Surrounding Fuels}

The mechanism here is similar to that involved in flame spread, except that it is now the lean limit of the vapors from the remote fuel which must be reached. Unless the fuel is directly over the pool, energy transfer is purely radiative in nature. A limited amount of work has been directed at determining minimum irradiances for ignition of materials. For instance, canvas ignites at about $2.1 \mathrm{~W} / \mathrm{cm}^{2}$, pine at $3.3 \mathrm{~W} / \mathrm{cm}^{2}$, black rubber at $6.2 \mathrm{~W} / \mathrm{cm}^{2}$, all for 3 -minute exposures [9]. Knowing this, we also need to obtain the incident radiance from the pool fire plume. Such measurements are dependent on the opacity and 
temperature of the flames, their spatial extent and the view factor from the remote fuel. Ploneering studies underway at the Factory Mutual Research Corporation [8] are beginning to yield such information. However, at this date we are unable to quantify this hazard.

An implicit assumption here is that the effective flame radiation is alike for all fuels, i.e., it is continuum, gray-body emission with little contribution from discrete bands [8]. This is reasonable since, in this configuration, much soot is generated, and the hot soot dominates the emitted energy. However, while these flames appear to be orange on a black soot background, the flames from silicone fluids appear more yellow and the "soot" white. Different radiant spectra could lead to different absorptivities by remote fuels. We therefore investigated the applicability of the gray-body assumption for a typical silicone fluid and found that the emission spectrum and temperature are similar to those for hydrocarbons. Details of this study are presented in appendix A.

\subsubsection{Dependence of Pool Burning Rate on Prevailing Atmospheric Conditions}

For the large, turbulent fires of concern here, breezes affect the burning rate and thus the heat release rate [5]. Even drafts as small as $0.5 \mathrm{~m} / \mathrm{s}$ increase the oxygen availability, increasing the otherwise diffusion-limited transport to the flame front. This increases the completeness of reaction, and thus the flame temperature. Since the flame radiation is proportional to the fourth power of the temperature [10], more energy is incident on the fuel surface, increasing the evaporation rate. This increase in burning rate is tempered somewhat by the fact that as the air velocity increases, the flames are displaced from the fuel pool, which reduces the radiative feedback. Eventually, this leads to the flames being blown off the pool and being extinguished. For hydrocarbon fuels this occurs at relatively high air velocities which are not likely to be encountered around indoor transformers [11]. 
Moreover, for pool dlameters of the order of one meter or larger, there is evidence that the natural turbulent entrainment of oxygen reduces the importance of even strong wind effects to less than 20 percent [12].

A second necessary consideration is vitiation or oxygen depletion of the incoming air supply. A one square meter pool fire can theoretically consume all the oxygen in about one cubic meter of air in one second. Thus the pool can be its own vitiation source, certainly so in small rooms. Under reduced oxygen concentrations, the burning rate is also reduced, and at some level the fire is extinguished. For small, diffusion-controlled fires of hydrocarbons where heat losses to the pan are important, this occurs at 15-16 percent oxygen [13]. For large, turbulent fires, limits closer to 10 percent have been observed $[14]$.

\subsection{Pool Fire Performance Tests}

It is abundantly clear from the earlier discussion that the available standard tests which might be used to assess fluid flammability cannot represent the actual situation. Realizing this, the involved community has continued to address the problem and is arriving at credible, if partial, solutions.

\subsubsection{The Factory Mutual Approval Scheme}

During the past several years, the Factory Mutual Research Corporation (FMRC), with the assistance of industry and government, has constructed a philosophy for hazard reduction, performed experimental and theoretical research, and now has issued a test sequence for recognition of less flammable transformer fluids [15]. The demands placed on the fluid are intended to reduce the likelihood of structural damage to the roof of a noncombustible building with noncombustible occupancy. Situations in which either the building or the fluid fail to qualify must be dealt with by a selection of containment or suppression devices. 
The first requirement is that the fluid have a fire point of at least $300^{\circ} \mathrm{C}$, consistent with the current National Elecrical Code. This temperature is sufficiently high to afford resistance to small ignition sources, such as matches, but is still low enough to be met by the several classes of commerclal fluids discussed earlier. There appears to be no technical basis for selecting this particular value.

Next, the transformer must be located within a dam that is at least four times the area of the transformer tank and is deep enough to contain all the fluid in the event of a spill. Should the fluid be ignited, and it is assumed that it will be and become fully involved in flames, this insures that the flames will not spread along the floor. It assures a fixed flame geometry.

This leads to the third requirement--a maximum allowable rate of convective heat release. In a nonflammable building with nonflammable contents, the risk of extensive fire loss is mainly to the structure itself. If the ceiling over the fire is overheated, collapse of the roof could ensue. Plume theory was used to develop curves which provide a maximum allowable heat release rate for a given ceiling height, ceiling material and pool area. The accuracy of these curves has been experimentally verified [16]. The heat release rates are to be measured by FMRC using a procedure described below. This approval scheme is already active.

With the assumptions involved and the limited applicability, this is indeed a conservative approach. However, it is the first of its kind to combine performance tests with theoretically-derived, operationally-verified performance limits and apply them to the reduction of fire risk. Hopefully it will serve as a model for future test development. 


\subsubsection{Rate of Heat Release Determinations}

The FMRC approach to measuring convective heat release rates is to burn large pans of the fluid in a building of very high ceiling and measure the temperature rise of an array of thermocouples suspended above the plume [17]. A radiative component is also determined, using a single radiometer, for fluid use in outdoor transformers located near a vulnerable wall. The pan was selected to be $1.73 \mathrm{~m}$ in diameter and $7.6 \mathrm{~cm}$ deep. As Hottel noted [18], for fires above one meter in diameter, the mass burning rate per unit surface area is independent of that surface area. Thus the one measurement should be characteristic of the fluid for the range of dike areas expected. The fluid is ignited by an outer, concentric, ring-shaped pan which is filled with n-heptane floating on water. The heat release measurements are taken after the entire surface of the candidate fluid has ignited and the ignition trough has burned out.

Tests have been run with samples of most commercial candidate fluids [17]. The hydrocarbon fuels all had similar convective and radiative heat release rates of approximately $700 \mathrm{~kW}$ per square meter of pan area and $400 \mathrm{~kW} / \mathrm{m}^{2}$, respectively. The silicone fluid values were about $50 \mathrm{~kW} / \mathrm{m}^{2}$ and $30 \mathrm{~kW} / \mathrm{m}^{2}$, and were less precisely determined since the fluid crusts during burning and this gives non-steady values.

The RTE Corporation also ran a series of 12 tests. They used a similar pan, but ignited the fluid with a propane burner. A conceptually similar, but dimensionally different thermocouple array was used for the convective measurements. A different radiometer and view factor was used. As of this date, only a preliminary report [19] has been issued. It presents the results for one hydrocarbon test and one silicone test. The hydrocarbon fluid convective and radiative components were $400 \mathrm{~kW} / \mathrm{m}^{2}$ and $330 \mathrm{~kW} / \mathrm{m}^{2}$, respectively. The silicone fluld values were $150 \mathrm{~kW} / \mathrm{m}^{2}$ and $340 \mathrm{~kW} / \mathrm{m}^{2}$. 
Under contract from Dow-Corning, the Southwest Research Institute (SwRI) burned pool fires of high performance hydrocarbon and silicone fluids [20]. These were similar to those burned in the other two sets of tests. Pan sizes differed somewhat from the prior studies, and a propane burner was the ignition source. The total hydrocarbon heat release rates were about $1200 \mathrm{~kW} / \mathrm{m}^{2}$; the silicone was about $150 \mathrm{~kW} / \mathrm{m}^{2}$.

Although multiple tests were run by both FMRC and SwRI, no indicator of reproducibility was provided in either report. Clearly, secondary changes in ignition and measurement techniques have a sizable effect on the reported heat release rates, indicating a need for standardization, if not refinement, of the procedures. Factory Mutual has since performed more tests and is establishing such limits of uncertainty [16].

\subsection{Aging of Fluids}

In the preceding discussion, it has been tacitly assumed that the appropriate fluid to be studied, and eventually tested, is the fresh fluid. Since transformers have lifetimes of decades, some consideration must be given to the likelihood that the fluid will undergo some partial metamorphosis during this period. Changes in chemical structure could lead to variations in the fluid's flammable limits and thus its fire point.

The thermal degradation of gaseous organic molecules is well-studied [21] and in the high pressure limit is similar to the degradation of liquids [22]. The process is, in its early stages, unimolecular, and the buildup of decay products is linear with time. The reaction rate rises exponentially with increasing temperature. Thus laboratory scaling of these processes to shorter lifetimes is a relatively easy process. The complexities of the transformer interior negate such a simple approach. While the fluid temperature may reach $150^{\circ} \mathrm{C}$ near the core, it may be nearly $100^{\circ} \mathrm{C}$ lower near the case. In addition, the 
fluid is perturbed by intentional additives, such as antioxidants, and unintentional components, such as extracts from paper insulation or metal atoms from the case and coils. Their effects on the fluid decay rate are neither kinetically simple nor spatially uniform. This is an area that needs attention.

In this section, the major topic of concern is electrical aging. During its lifetime, a fluid is subjected to strong electrical fields and perhaps partial discharges. As these occur, there are formed low molecular weight gases, which may dissolve in the fluid or occupy the ullage above, lower molecular weight fluid components, and higher molecular weight fluid components. Since we are concerned with the ignitability of the fluid, it is the former two sets of products that matter. The lower molecular weight fluid molecules volatilize at lower temperatures. By Raoult's Law, an increase in their concentration in the liquid will produce a richer vapor above, thus lowering the fire point. The electrical generation of gaseous products produces the same result. A lower fire point increases the likelihood of ignition by smaller pilot sources.

We are performing preliminary experiments to establish the means for evaluating the enhanced flammability of electrically degraded fluids. Our approach is to measure the change in vapor pressure of a fluid induced by the electrical stress. Full details will appear in a later report. A conceptual description follows.

The insulating fluids under investigation were found to contain dissolved air. Thus the fluid was gently heated, pumped to a stable vapor pressure, about $10 \mathrm{~m}$ torr $(1.3 \mathrm{pa})$, and the vapor pressure measured as a function of temperature. The sample was then transferred to a $\sim 150 \mathrm{~cm}^{3}$ high voltage cell and subjected to a voltage of $25 \mathrm{kV}$ for six hours. The vapor above the fluid was then collected and analyzed with a mass spectrometer by direct injection. Following removal of this vapor, the vapor pressure of the fluid was again measured. 
Three experiments with silicone fluid resulted in vapors consisting of water, nitrogen and oxygen. These were probably the result of further outgassing. In one case, several electrical breakdowns occurred and some hydrogen was produced. This is consistent with a prior study on arc-decomposed fluids [23]. A mineral oil sample also experienced arcing with the resulting generation of hydrogen. The comparative vapor pressure measurements are still in progress.

\section{THE VIOLENT RUPTURE SCENARIO}

\subsection{Description of Hazard}

In this type of transformer failure, the potential for damage is far greater than that discussed earlier. Here, a typical fault of ten begins as turn-to-turn current leakage, gradually involving more turns and progressing to coil-to-coil or coil-to-ground discharge [24]. This suddenly releases a large pulse of energy, generally in about one ac cycle. This in turn thermally expands the fluid, forcing it against the case, which yields. Upon contact with the air, the now hot combustible gases dissolved in the fluid or in the ullage autoignite and then ignite the escaping fluid. A violent emission of liquid blobs ranging in size from microns to centimeters in diameter occurs. Depending on the fluid and conditions, all or some of the droplets may be flaming. Thus they may ignite other fuels by aerial impact. In addition, upon settling to the ground they may form ignited pools which may flow to other fuels or may cause structural damage as noted in section 3 .

We have assumed that we are not in a position to reduce the frequency of electrical transformer failures. Thus the discussion that follows deals only with ameliorating the impact of such explosions. 


\subsection{Applicability of Standard Test Methods}

Because of the highly specialized nature and lack of detailed study of this type of event, and the track record of askarels, no test methods have been developed specifically for it. The standard ignition temperature measurements do not apply since the arc energy is so large. In addition, combustible gases from arc-decayed fluid and paper insulation provide an intense piloted ignition. The fluid is blown out in a pulse, not with a sustained backing pressure, so steady state spray ignition tests are difficult to relate. In a nutshell, there is no premise for assessing the fire safety of a fluid in this mode. There is no voluntary standards committee work in this area at present.

\subsection{Explosion Tests}

If one has available a source of high current $(\approx 5000$ amperes) at high voltage ( $~ 25000$ volts), it is possible to simulate the sudden electrical failure of a transformer. Such high power laboratories are few in number and expensive to operate. Nonetheless, both General Electric and RTE have performed tests of this type [25]. Faults were induced in containers of potential and current dielectric fluids. The outcomes were filmed, yielding mainly qualitative data. Mineral oil produced a huge, black and orange fireball. Silicone fluids generally produced large white clouds with far less extensive flames. The high performance hydrocarbons similarly outperformed the mineral oil. Surprisingly, a PCB explosion yielded a large black cloud with some orange flames. Thus, even the "nonflammable" fluid could be ignited. These pioneering tests, as crude as they were, have provided a "feel" for further studies. However, because of the perceived cost-benefit ratio, an extensive research program was not pursued.

Recently, the National Electrical Manufacturers Association (NEMA) proposed and was awarded a contract to study explosions in a less expensive, more controllable manner. Using a model by Barkan [22], 
black powder charges would be designed to simulate the rate of energy release from electrical failures. Various-sized transformer cases and complete transformers are to be exploded, and the reproducibility determined. The result will be an assessment of whether this approach can be used in further studies of this scenario. In addition, several combustible materials, such as fiberboard, polystyrene, and plywood, will be placed at discrete locations about the explosion site. Their ignitability by ejected fluid will be determined visually, and the results used to test the model described in the next section of this report. The project has begun, and completion is scheduled for early 1980 .

\subsection{Model for the Ignition of Remote Fuels by Flaming Droplets}

In the event of a violent transformer explosion, the major fire hazard results from secondary ignition by ejected, flaming fluid. The burning globules impact some combustible material, locally heat it above its fire point, and ignite it. This hazard is clearly reduced if the fluid droplets lose too much heat to the contacted surface and are themselves extinguished. This would result in the need for the target material to be raised to its (much higher) autoignition temperature for flaming to ensue. Our purpose, then, is to identify the ignitiondetermining fluid and target material properties and ascertain whether control of them is feasible.

The simplified physical model is as follows. A flaming liquid droplet impinges on a horizontal surface, forming a thin, hot layer with flames above it. Prior to impact, the liquid has reached a steady-state temperature with endothermic evaporation balancing the radiant heating from the flames. Upon impact, the liquid is initially isothermal at $\mathrm{T}_{\mathrm{L}}$, which is above the liquid's fire point. Since the liquid is thin, it is assumed to remain isochermal. However, the value of $\mathrm{T}_{\mathrm{L}}$ will approach the fire point as heat is removed by the solid. The solid surface itself is non-porous, thermally thick, and initially at $\mathrm{T}_{\mathrm{o}}$, the room temperature. As time progresses, the temperature profile of the system behaves as shown in figure 1 . 
The problem is one of one-dimensional heat transfer to a semi-infinite slab. We assume that heat is lost from the liquid only to the solid. Within the solid, the spatial and temporal temperature profiles are described by the Fourier equation [26]:

$$
\frac{\partial T}{\partial t}=\alpha \frac{\partial^{2} T}{\partial^{2} x}
$$

with boundary conditions on the solid of $\mathrm{T}=\mathrm{T}_{0}$ at $\mathrm{t}=\mathrm{o}$ for all values of $\mathrm{x}, \mathrm{T}=\mathrm{T}_{\mathrm{L}}$ at $\mathrm{x}=0$ for all $t\left(\mathrm{~T}_{\mathrm{L}}\right.$ will vary with time), and $\mathrm{T}=\mathrm{T}_{0}$ at $\mathrm{x}=\infty$ for all $t$. The solution for this is

$$
\frac{T-T_{0}}{T_{L}-T_{0}}=1-\operatorname{erf}\left(\frac{x}{\sqrt[2]{\alpha t}}\right)
$$

where $\alpha$ is the thermal diffusivity of the solid. This expression assumes $T_{L}$ is a constant, whereas in this model, $T_{L}$ w1ll decrease from its initial value, $T_{L}(0)$, to the fire point of the fluid, $T_{F P}$. At $\mathrm{T}_{\mathrm{FP}}$, extinction occurs. The equation is valid when $\mathrm{T}_{\mathrm{L}} \sim \mathrm{T}_{\mathrm{FP}}$, and $\mathrm{T}_{\mathrm{L}}-\mathrm{T}_{\mathrm{FP}}$ generally will be much less than $\mathrm{T}_{\mathrm{L}}-\mathrm{T}_{\mathrm{o}}$ for high fire point fluids. Hence, we will assume the validity of the solution, subject to later examination.

The next expression needed is for the energy loss rate per unit area transferred from the fluid to the solid, $\dot{q}^{\prime \prime}$ [26].

$$
\dot{q}^{\prime \prime}=-\int_{0}^{\infty}\left(\mathrm{T}-\mathrm{T}_{0}\right) \mathrm{c}_{s} \rho_{s} d x
$$

where $c_{S}$ and $\rho_{S}$ are the specific heat and density of the solid, respectively. 
Substituting equation (1) into (2),

$$
\dot{q}^{\prime \prime}=-\int_{0}^{\infty}\left(T_{L}-T_{0}\right)\left[1-\operatorname{erf} \frac{x}{2 \sqrt{\alpha t}}\right] c_{s} \rho_{s} d x
$$

Assuming the heat capacity and density of the solid change little as a function of temperature,

$$
\dot{q}^{\prime \prime}=-\left(T_{L}-T_{0}\right) c_{s} \rho s \int_{0}^{\infty}\left[1-\operatorname{erf}\left(\frac{x}{2 \sqrt{\alpha t}}\right)\right] d x
$$

which integrates to:

$$
\dot{q}^{\prime \prime}=-\left(T_{L}-T_{0}\right) c_{s} \rho s \quad \sqrt{\frac{\alpha}{\pi}} t^{-1 / 2}
$$

Integrating with respect to time, and withdrawing the lost energy evenly throughout the liquid $\left(q^{\prime \prime}=\mathrm{dC}_{L}{ }^{\rho}{ }_{L} \Delta \mathrm{T}_{\mathrm{L}}\right.$ ), we obtain an expression for the temperature decrease of the fluid:

$$
\Delta T_{L}=\frac{2 c s^{\rho} s}{c_{L} \rho_{L}} \frac{T_{L}-T_{0}}{d} \sqrt{\frac{\alpha}{\pi}} t^{1 / 2}
$$

where the subscript $L$ refers to the fluid and $d$ is the thickness of the fluid layer. We can rearrange this equation to get the contact time in which the fluid temperature would be reduced from its starting temperature to its fire point, $\Delta \mathrm{T}_{\mathrm{L}}$.

$$
t=\left[\frac{\Delta T_{L[c \cdot \rho]_{L}} d}{2 \sqrt{\frac{\alpha}{\pi}}[c \cdot \rho]_{s}\left(T_{L}-T_{o}\right)}\right] 2
$$


Before proceeding further with this quite approximate model, it is valuable to calculate a typical magnitude of a flame quenching time. For silicone fluid, mineral oil and several high performance hydrocarbons, the specific heat is about $1.5 \mathrm{~J} / \mathrm{g}-\mathrm{K}$ and the specific gravity is about $0.9 \mathrm{~g} / \mathrm{cm}^{3}$. The thermal diffusivity is the thermal conductivity ( $3 \times 10^{-3} \mathrm{~J} / \mathrm{s}-\mathrm{cm}-\mathrm{K}$ for wood) divided by the product of the density $\left(0.8 \mathrm{~g} / \mathrm{cm}^{3}\right.$ for wood) and specific heat $(2.4 \mathrm{~J} / \mathrm{g}-\mathrm{K}$ for wood). For the moment, we will assume the liquid layer is about $0.3 \mathrm{~cm}$ thick. The fluids of interest will have fire points in the range of $300^{\circ} \mathrm{C}$, and $\mathrm{T}_{0}$ will generally be about $25^{\circ} \mathrm{C}$. We will use a value of $50^{\circ} \mathrm{C}$ for $\Delta \mathrm{T}_{\mathrm{L}}$. For wood, then, $t$ is about one half of a second. This is far less than the ignition time for the wood [27].

With this in mind, it is now important to ascertain whether there are any critical fluid properties that can be used to evaluate this ignition risk in realistic cases where far more fluid might land on the solid and where large flames might cause radiative heating of the solid. As already mentioned, the thermal properties of the wide range of currently-known dielectric fluids do not vary much. Furthermore, the liquid temperatures during flaming and the fire points are relatively uniform. By contrast, fluid surface properties offer some hope. Fluids that preferentially form small droplets upon expulsion have a lower probability of delivering large quantities of fluid to any one surface. Fluids that wet the impacted surface well will form thin, readily cooled layers. These aspects need further investigation.

From this crude model, we can also begin to refine the coarse terms "combustible" and "noncombustible" used in the National Electrical Code. Some differentiation can be made on the basis of thermal properties. In terms of this scenario, solids with higher values of heat capacity, density and thermal conductivity will be less ignitable. In addition, solids whose surfaces resist droplet adhesion or, at the other extreme, promote good thermal contact will also perform favorably. This is also a line of study which would be worth pursuing. 


\section{EVALUATING ALTERNATIVE FIRE SAFETY STRATEGIES}

As with any issue concerning public safety, the dielectric fluid flammability problem has two aspects. Heretofore, this report has dealt with scientific characterization of the fire phenomena. In this section, we address the equally important question of how to select approaches to achieve a desired degree of fire safety.

There are inherent difficulties in regulating the safety level of transformer installations. There is a lack of available, detailed case data on past transformer fires. The fire ignition and spread phenomena are only qualitatively understood. The pertinence of available test methods is questionable. Experts disagree on technical issues and may be biased by disciplinary or commercial interests, and above all there are serious value judgments to be made regarding the degrees of property loss, accidental injuries and deaths that are acceptable.

The methodology of decision analysis [28] provides a structuring of this problem. By creating a formalism of non-exclusive alternatives, we are able to reduce a complex problem to a series of specific issues. Probabilistic methods can then be used to address the uncertainties. Existing expertise can answer the purely technical aspects, and explicit value judgments can be introduced to facilitate comparisons. In the end, we have a dollar value for the costs and losses associated with each possible regulatory decision. These can then be examined in view of the degree and type of fire safety desired. This approach has recently been successfully applied to the equally complex reduction of upholstered furniture fire loss [24].

In the present study [30], a decision tree was constructed to estimate the losses from transformer fires in terms of property damage, injuries and deaths. Branches on the tree included the probability of a fluid leak, probability of ensuing transformer failure, location of tank rupture, fraction and volume of fluid emitted, likelihood of ignition, 
degree of fire protective construction present, fuel load in the room, and extent of fire spread. Using NFIRS data, average losses were calculated for contemporary transformer failures under historicallyevolved regulations (defined as the "base case"). Since essentially no PCB-filled transformers have caused fire damage and since relatively few transformers were filled with other high performance fluids at the time interval counted, it was assumed that all fires involved mineral oil.

Seven intervention strategies were then evaluated by calculating their cost of implementation and using the decision tree to estimate their effectiveness:

1. Requirement of a periodic, in-use fluid testing program consisting of acidity level, dielectric strength, interfacial tension, color, and combustible gas analysis.

2. Requirement of a $300^{\circ} \mathrm{C}$ fire point.

3. Requirement of a "fire-proof" fluid, with a performancerelated standard yet to be developed.

4. Requirement that the transformer be contained in a room of 3-hour fire resistant construction.

5. Requirement that the transformer be contained in a room of 1-hour fire resistant construction.

6. Requirement of a dike around the transformer to contain any spilled fluid and a metal sheet around the transformer to eliminate spreading of sprayed fluid.

7. No protection at all. 
These were then compared with each other and with the aforementioned base case (which includes partial use of some of the above protection measures). In doing so, dollar values were assigned to human losses. Sensitivity analyses were performed to determine the dependence of the outcome on the values of the various input parameters.

The expected annual losses after implementing any or none of these strategies are listed in table 1 . The cost-plus-loss figures over the transformer lifetime are shown in table 2. Note that the effect of each strategy on deaths, injuries, and property loss is calculated independently, thus the fractional reductions in the three types of losses are not necessarily equal. As one would have guessed, the data show that safety costs money.

The concept of risk attitude now becomes pivotal. The regulator must decide what the public will not tolerate and what costs are acceptable. This decision is inevitable. The improvement lies in the existence of concrete data to base his judgment. For instance, if over one thousand injuries and thirty deaths a year are considered small compared to some other pressing demand on his resources, the "no protection" alternative might be selected. If the regulator anticipates a public outcry over even one fire death, there are three possible approaches, and their relative merits can be considered.

It is important to note that the conclusions are based on the best data available and consider only a few representative strategies. While these cover the three basic approaches (inspection, fluid upgrading, and physical barrier), clearly further thought and commercial progress should suggest further ideas. The model itself can also be made more sophisticated as needed. 


\section{RECOMMENDATIONS FOR FURTHER WORK}

\subsection{Assessment of the Current Status}

At this time, no new PCB-filled transformers are being supplied, and there is mounting pressure to retrofill or replace the existing units. The former alternative is problematic [31]; both alternatives are costly. Nonetheless, existent PCB-filled units will disappear for two reasons. First, many transformers eventually leak, and there will be no PCBs to top them off. Second, the leaked fluid poses potential health problems as noted in the recent case cited in appendix $B$. Both the hazard and the outcry are intolerable.

The NFIRS data indicate that the current variety of transformer installations and environments pose relatively little fire risk. It is assumed that this record will be sustained. This will be complicated by the fact that older buildings may not be able to support fire-resistant enclosures, and the only currently-allowed exceptions are situations approved by the Factory Mutual standard, i.e., noncombustible occupancy in a noncombustible structure. New buildings will have to be designed with the strength and space for vaults, an expensive consideration beyond the cost of the vault itself.

At present, there is no pending relief, in the form of enlightened recommended practices, from the expense or even impossibility of rigid adherence to current standards.

\subsection{Needed Test Development}

There are three components necessary to advance the possibility of lower cost fire safety. The first is to model the specific fire hazards of the fluids and identify which fluid properties determine them. Our current study has performed much of this. The second is to characterize the surroundings in terms of their contribution to a fire initiated 
by the transformer. After these, the third step is to use this knowledge to create germane test methods to identify fluid and occupancy combinations that are compatible with the desired degree of fire safety. We have learned enough to project what these might look like. In reading the ensuing discussion, it should be remembered that it is still necessary to identify parties or agencies that will endorse such tests and concepts upon their development.

\subsubsection{Fluid Ignitability}

Should the fluid escape from the transformer case and form a puddle, there will be a minimum energy input rate if flames are to ensue. The current assumption is that this will be available. Rather, for any given installation, the surrounding energy sources and the ignition potential of the transformer itself should be quantified. The fluid should be physically bounded, as noted in the Factory Mutual scheme. A heat balance model should be constructed involving the heat transfer mode (radiative, convective or conductive) from the ignition source and the heat dispersion capability of the fluid and its container. These loss terms would rely mainly on the thermal properties of the fluid and the container. The criterion for acceptability would be whether the eventual maximum fluid temperature reached the fire point or autoignition temperature, the choice depending on the nature of the igniter at hand. A fluid that can resist all available ignition sources should be relatively fire-safe.

The test method for verification should involve a thermally thick pool of the fluid, the depth being determined using such studies as reported in references [6] and [7]. The pool should be large enough to simulate actual usage and to reduce the edge effects, which create excessive heat loss. A diameter of one meter and a depth of ten centimeters is a reasonable a priori estimate. Thermal sources would be simulated by an immersed electrical coil, flaming sources by an impinging propane torch. Each fluid would be given a rating based on 
the magnitude of ignition sources it could withstand. If the rating level exceeds the ignition sources in a given usage, it would no longer be necessary to require the building or surroundings to be noncombustible under the slow leak scenario.

\subsubsection{Radiant Ignition of Surrounding Materials}

Should a fluid be found ignitable under the above criteria, it still may be relatively safe. Since it is geometrically contained by a dam, its means of igniting further fuels is mainly radiative. The radiation may arise from the fire plume itself or from the layer of hot gases which would accumulate in the upper portion of the room [32]. There are solid efforts to characterize the plume radiation [8] and the radiative ignition of fuels [33]. There is already some data on the minimum irradiances or minimum time exposures for ignition of various fuels $[9,34]$. More such data are sorely needed. Ideally, simple comparison of the fire radiances with fuel susceptibilities would provide an indicator of compatibility. For verification, at least a few fullscale room fire tests should be conducted.

Successful ignition resistance is the most convenient outcome for establishing a degree of fire safety. Ignition delay times that are long compared to, perhaps, halon extinguisher or sprinkler activation times could also be accommodated.

\subsubsection{Contact Ignition of Surrounding Materials}

In the event of already flaming fluid escaping from the case, we need to know if surrounding materials can be ignited by impacting fluid before the fluid extinguishes. This situation is most likely to occur under the violent rupture scenario. The model presented in section 4.4, a first attempt at understanding this, will be tested in the current NEMA project. Extension of the model, in directions indicated earlier, and further experiments will probably be necessary. The important 
characteristic is whether all the ejected fluid is flaming. If the radius of the fireball from the explosion is significantly smaller than the throw radius of the fluid or if the falling globules are no longer flaming, the fluid possesses a reduced potential for further ignition.

One possible approach to a correlative laboratory test method involves the currently-discarded spray test. As noted by Factory Mutual [17b], all the current candidate fluids will ignite under certain spray conditions. Some set of such conditions should be selected, and spray fires established. Samples of various materials would then be introduced into the spray at appropriate locations for appropriate time intervals. Selection of values of these parameters would require some further study. The fluids which failed to ignite all appropriate samples would be designated acceptable for use under this scenario. Conversely, materials which resisted ignition from a given fluid spray could be designated "compatible" with that fluid. This would provide a basis for defining an occupancy as "noncombustible".

\subsubsection{Damage to the Building}

Some aspects of this have been discussed above: the building's exposed construction and interior finish materials would be treated the same as its contents. If these materials are noncombustible, the Factory Mutual scheme addresses the avoidance of structural damage. Thus this consideration is moderately well in hand. The only further instance of concern is when the building materials are not ignitable by the fluid, yet are not steel or concrete. Extension of the Factory Mutual calculations to include structural loss of such materials, e.g., wood, would complete the picture.

\subsection{Epilogue}

The most serious need is for more detail on any transformer-initiated fires that do occur. This will ensure the thoroughness of the fire 
safety analysis. While qualification of fluids for general usages could be based on a general series of criteria, it would be operationally and economically more feasible for the selected fluid to meet the specific flammability constraints of its specific usage. Lest this be considered as impractical, such a system is currently used for portable fire extinguishers [35]. The formalism of decision analysis provides a means for evaluating such an approach.

\section{ACKNOWLEDGMENTS}

A project of this extent requires the contributions of many, both as participants and consultants. In particular are three colleagues from the Center for Fire Research: Dr. Gary Mallard, who devised the quenching model described in section 4.4; Michael Manka, who performed the fluid aging tests with the cooperation of Drs. Robert Hebner and Edward Kelley of the NBS Center for Electronics and Electrical Engineering; and $\mathrm{Dr}$. Kermit Smyth, who performed the flame radiation measurements described in appendix A. Dan Levinthal of Harvard University performed the decision analysis in section 5, in consultation with Dr. Fred Offensend of SRI International and Benjamin Buchbinder of the Center for Fire Research.

Invaluable advice and reference materials were provided by representatives of the Factory Mutual Research Corp., Dow-Corning Corp., Westinghouse Electric Corp., General Electric Co., RTE Corp., Doble Engineering Co., the National Electrical Manufacturers Association, and Versar, Inc. The IEEE S-32 Committee on Fluid Dielectrics served as a major resource.

The author thanks his Center for Fire Research colleagues, Marva Brown for typing the manuscript, Alan Gomberg for accessing the NFIRS data, and Dr. Clayton Huggett for his helpful advice, especially in the early stages of the project. 


\section{REFERENCES}

[1] National Electrical Code, 1978 Edition, National Fire Protection Association, Boston, Mass.

[2] National Fire Incident Reporting System, U.S. Fire Administration, Washington, D.C.

[3] Fire in the United States, U.S. Fire Administration, Washington, D.C. (1978).

[4] Miller, D. B. et al., An appraisal of tests and standards for the evaluation of electrical insulating fluids, Nat. Bur. Stand. (U.S.), NBSIR 76-1054 (1976).

[5] Blinov, V. I. and Khudiakov, G. N., Diffusion Burning of Liquids, English translation, National Technical Information Service, AD 296762, Springfield, Va. (1961).

[6] Hall, A. R., Pool Burning, in C. F. H. Tipper, ed., Oxidation and Combustion Reviews, Vol. 6, Elsevier, New York (1973).

[7] Mackinven, R., Hansen, J. G. and Glassman, I., Comb. Sci. and Tech. 1, 293 (1970).

[8] de Ris, J., 17th Symposium (International) on Combustion, p. 1003, The Combustion Institute, Pittsburgh, Pa. (1979).

[9] Smith, W. K., Ignition Chart for Fire Bomb Range Calorimeter Plates, Technical Note 40604-10, Naval Weapons Center, China Lake (1968).

[10] Richards, J. A., Sears, F. W., Wehr, M. R. and Zemansky, M. W., Modern University Physics, Addison-Wesley Co., Reading, Mass. (1960).

[11] Hirst, R. and Sutton, D., Comb. and Flame 5, 319 (1961).

[12] Burgess, D. S., Strasser, A. and Grumer, J., Fire Res. Abstr. and Rev. 3, 177 (1961).

[13] Nelson, G. L. and Webb, J. L., J. Fire and Flam. 4, 210 (1973).

[14] Gann, R. G. et al., Comb. Sci. and Tech. 18, 155 (1978).

[15] Approval Standard - Less Flammable Transformer Fluids, Factory Mutual Research Corp., Norwood, Mass. (May 30, 1979).

[16] Hemstreet, R., Factory Mutual Research Corp., private communication. 
[17a] Factory Mutual Loss Prevention Data Sheet 5-45/14-85, Factory Mutual Research Corp., Norwood, Mass. (1979).

[17b] Hemstreet, R., Flammability Tests of Askarel Replacement Transformer Fluids, Serial 1A7R3.RC, Factory Mutual Research Corp. (1978).

[18] Hottel, H. C., Fire Res. Abstr. and Rev. 1, 41 (1959) and errata on final page of 1 , No. 2 (1959).

[19] Experimental Determination of Burning Characteristics of Transformer Dielectric Fluids, RTE Corp. (1979).

[20] Kanakia, M., Characterization of Transformer Fluid Pool Fires by Heat Release Rate Calorimetry, Final Report SwRI Project 03-5344-001, Southwest Research Institute (1979).

[21] Benson, S. W., Thermochemical Kinetics, John Wiley \& Sons, Inc., Somerset, N.J. (1968).

[22] Gardiner, W. C., Jr., Rates and Mechanisms of Chemical Reactions, W. A. Benjamin Inc., New York (1969).

[23] Kuwahara, H. et a1., Study of Explosion and Fire Hazards of Silicone Liquid Under Arc Conditions. Paper presented at the IEEE International Symposium on Electrical Insulation, Montreal, 1976.

[24] Barkan, P. et al., IEEE Transactions on Power Apparatus and Systems, PAS-95, 37 (1976).

[25] The author thanks General Electric and RTE for copies of the movies of these tests.

[26] Welty, J. R., Wicks, C. E. and Wilson, R. E., Fundamentals of Momentum, Heat, and Mass Transfer, John Wiley \& Sons, Inc., Somerset, N.J. (1976).

[27] Simms, D. L., Comb. and Flame 4 , 293 (1960).

[28] Raiffa, H., Decision Analysis, Introductory Lectures on Choices Under Uncertainty, Addison-Wesley Co., Reading, Mass. (1968).

[29] Helzer, S. G., Buchbinder, B. and Offensend, F., Decision analysis of strategies for reducing upholstered furniture fire losses, Nat. Bur. Stand. (U.S.), NBS Technical Note 1101 (1979).

[30] Levinthal, D., Applications of decision analysis to a regulatory problem: Fire safety standards for liquid insulated transformers, Nat. Bur. Stand. (U.S.), NBS-GCR-80-198. 
[31] Morgan, L. A. and Osthoff, R. C., Problems Associated With the Retrofilling of Askarel Transformers. Paper presented at the IEEE Winter Power Meeting, New York, 1977.

[32] Quintiere, J., Growth of Fire in Building Compartments, in A. Robertson, ed., Fire Standards and Safety, STP-614, American Society for Testing and Materials, Philadelphia, Pa. (1976).

[33] Kashiwagi, T., Comb. and Flame 34, 231 (1979).

[34] Hallman, J. R., Ignition Characteristics of Plastic and Rubber, $\mathrm{Ph} . \mathrm{D}$ Thesis, University of Oklahoma (1971).

[35] McKinnon, G. P. and Tower, K., eds., Fire Protection Handbook, National Fire Protection Association, Boston, Mass. (1976). 
Table 1. Expected annual national losses [30]

\begin{tabular}{lccc} 
Strategy & Property damage & Injuries & Deaths \\
\cline { 2 - 4 } Base case & $\$ 40.6 \mathrm{M}$ & 299 & 7 \\
Fluid testing & $\$ 26.7 \mathrm{M}$ & 197 & 33 \\
High fire point & $\$ 146.4 \mathrm{M}$ & 1040 & 0 \\
"Fire proof" $\mathrm{fluid}$ & $\$ 1.5 \mathrm{M}$ & 10 & 0 \\
3-hour vault & $\$ 14.7 \mathrm{M}$ & 118 & 0 \\
1-hour vault & $\$ 15.1 \mathrm{M}$ & 120 & 3 \\
Dike and sheet & $\$ 25.9 \mathrm{M}$ & 1953 & 34 \\
No protection & $\$ 148.2 \mathrm{M}$ & & \\
\hline
\end{tabular}




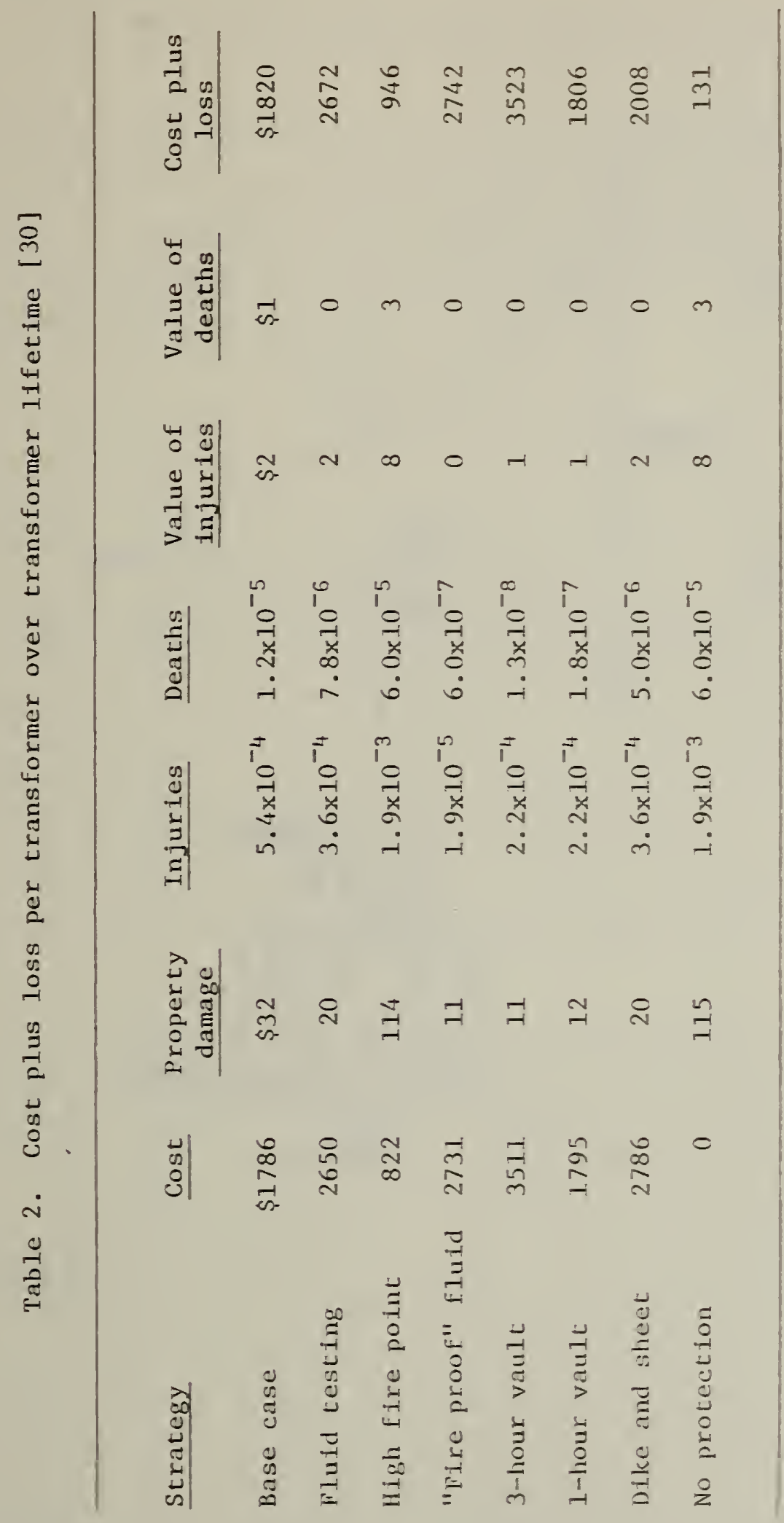



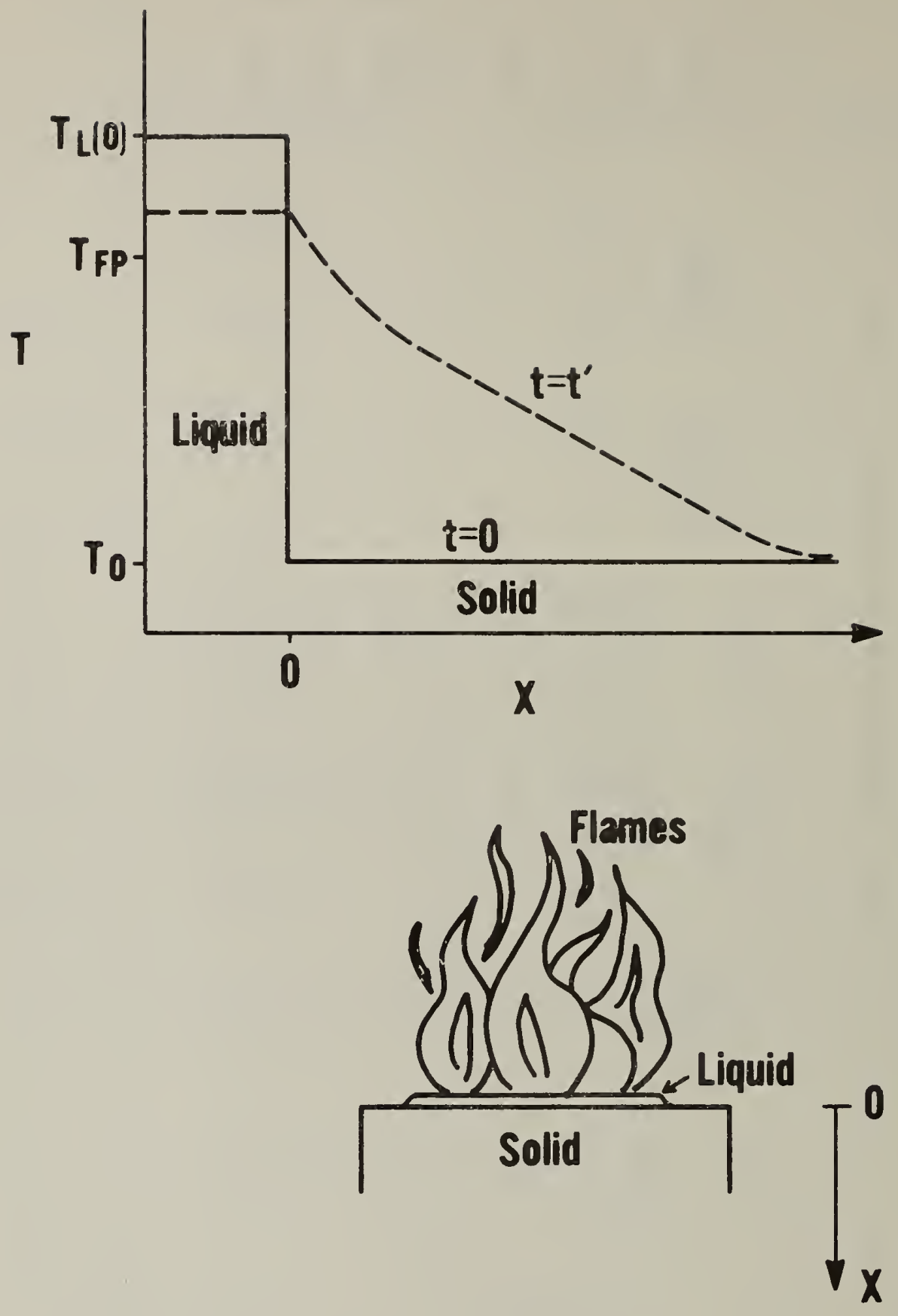

Figure 1. Temperature profiles of solid-liquid system at droplet impact $(t=0)$ and at some later time $\left(t=t^{\prime}\right)$ 


\section{APPENDIX A. COMPARISON OF RADIATION CHARACTERISTICS OF SILICONE AND HYDROCARBON FLUID POOL FIRES}

The purpose of this study was to resolve whether the emission spectra from fires of different fuels (hydrocarbon vs silicone) are different. To investigate this possiblility we burned small pool fires of typical hydrocarbon and silicone fluids and monitored their emission spectra with identical equipment.

\section{A.1 Experimental Procedure}

The hydrocarbon fluid used was NBS $\# 10$ pump oil, and the silicone fluid was a commercial $50 \mathrm{cs}$ sample. The pan employed for the pool fires measured $15 \mathrm{~cm} \times 13 \mathrm{~cm} \times 2 \mathrm{~cm}$. In this configuration there were two problems which arose in measuring emission spectra: (1) The flames were relatively small (15-25 $\mathrm{cm}$ in height) and somewhat turbulent. This led to considerable flame flicker, so that any emission signal exhibited large fluctuations at low frequency. (2) The amount of fuel burned was small, with the result that reasonably steady flames were obtained for only about 10 minutes. Thus, extensive signal averaging could not be utilized to reduce the low-frequency noise arising from flame flicker.

These experimental limitations dictated the optical equipment which could be used successfully. A careful monochromator scan of the emission would require a more steady light source and longer times than were available. Therefore, a simpler experimental setup was devised and is shown in fig. A-1. The emission was detected directly with an RCA 4840 photomultiplier tube. This tube is very sensitive at wavelengths down to the vacuum ultraviolet $(\sim 200 \mathrm{~nm})$ and has good response throughout the visible region $(400-700 \mathrm{~nm})$. A series of long-wavelength pass filters was used to isolate spectral regions $30 \mathrm{~nm}$ to $85 \mathrm{~nm}$ wide. Table A-1 presents the spectral characteristics of the specific filters used in this investigation. To avoid the photomultiplier tube "seeing" background and scattered light, a narrow 
viewing angle was defined by using two irises and a length of blackened pipe. This detection equipment was positioned to monitor emission from an area approximately $5 \mathrm{~cm}$ above the pan in which the pool fires were burned.

A data run proceeded as follows:

(1) The unfiltered light from the pool fire was allowed to irradiate the photomultiplier tube.

(2) The first long-wavelength pass filter was then inserted (50\% transmission at $670 \mathrm{~nm}$ ), thus attenuating the light reaching the photomultiplier tube.

(3) The filter was then removed, again allowing unfiltered light to reach the photomultiplier tube.

(4) The second long-wavelength pass filter was next inserted ( $50 \%$ transmission at $640 \mathrm{~nm}$ ), which attenuated the light somewhat less than the first filter.

(5) The second filter was then removed, and this procedure was repeated for the total of nine long-wavelength pass filters, listed in Table A-1.

\section{A. 2 Results and Data Analysis}

The raw data obtained using the procedure outlined above are shown in fig. A-2(a) for the hydrocarbon fluid and fig. A-2(b) for the silicone fluid. At least five similar runs were made for each fluid. Fig. A-2(c) presents the results of monitoring the emission from a $100 \mathrm{~W}$ tungsten light bulb. This light source is much more stable than the pool fires, and its emission spectrum is included to show the optical response of the detection equipment. 
The series of nine long-wavelength pass filters defines eight spectral regions between successive filters. These spectral regions are $30 \mathrm{~nm}$ to $85 \mathrm{~nm}$ in width. Thus, the net signal change between two successive filters indicates the amount of light reaching the photomultiplier tube in a specific spectral region. This net signal change must then be normalized for the photomultiplier sensitivity and the width of the spectral region. For example, consider filters 非 and 非 in table A-1. The net signal change obtained using these two filters is a measure of the light emitted in the 640-670 $\mathrm{nm}$ region. The raw net signal change obtained from data such as those in $\mathrm{figs.} A-2$ is then normalized by the photomultiplier sensitivity at $644 \mathrm{~nm}$ (the mean wavelength) and by the width of the spectral region (30 nm).

The results of analysis of the data in figs. A-2 are presented in fig. A-3(a) for the hydrocarbon fluid and fig. A-3(b) for the silicone fluid. Each data point represents the emission in a spectral region defined by two successive long-wavelength pass filters. Also indicated in figs. A-3 is the relative error in these determinations caused by the low-frequency flame flicker. The relative error is largest at shorter wavelengths where successive filters made little or no change in the detected light for both fluids (i.e., the relative error is largest where the net signal change is smallest).

Figs. A-2 and A-3 show immediately that there is little emission below $500 \mathrm{~nm}$ from either the hydrocarbon or the silicone fluid. For the hydrocarbon fluid it is difficult to measure net signal changes for filters beyond 非 $(50 \%$ transmission at $530 \mathrm{~nm}$ ). The data for the silicone fluid are more noisy (fig. $A-2(b)$ ), with the result that no signal change at all was reproducibly detected for filters 非6, 非8, or 非 9 .

Figs. A-3 also includes calculated gray-body (constant emissivity) spectral distribution curves. The temperatures chosen for comparison with the filter data were obtained from one-line, optical pyrometer measurements. A number of pyrometer measurements were made, giving 
$1370 \pm 30 \mathrm{~K}$ for the hydrocarbon fluid and $1470 \pm 50 \mathrm{~K}$ for the silicone fluid. The data from the long-wavelength pass filter results and from the pyrometer measurements are consistent within the error limits of the filter data. These error limits are sufficiently large that the filter data are compatible with gray-body spectral distribution curves spanning several hundred degrees. However, the same determinations made for the emission from the tungsten light bulb result in more narrow error estimates, and show that the pyrometer temperature value of $1790 \mathrm{~K}$ is significantly lower than the results from the filter data (fig. $A-3(c)$ ).

\section{A. 3 Conclusions}

(1) The spectral distribution of the emission from typical hydrocarbon and silicone fluids is similar, in that there is little emission from either fluid below $500 \mathrm{~mm}$ relative to the emission at longer wavelengths.

(2) The spectral distribution of the emission from these fluids is consistent with that expected for gray-body soot radiating at temperatures determined from pyrometer measurements. These temperatures are similar for the two fluids. 


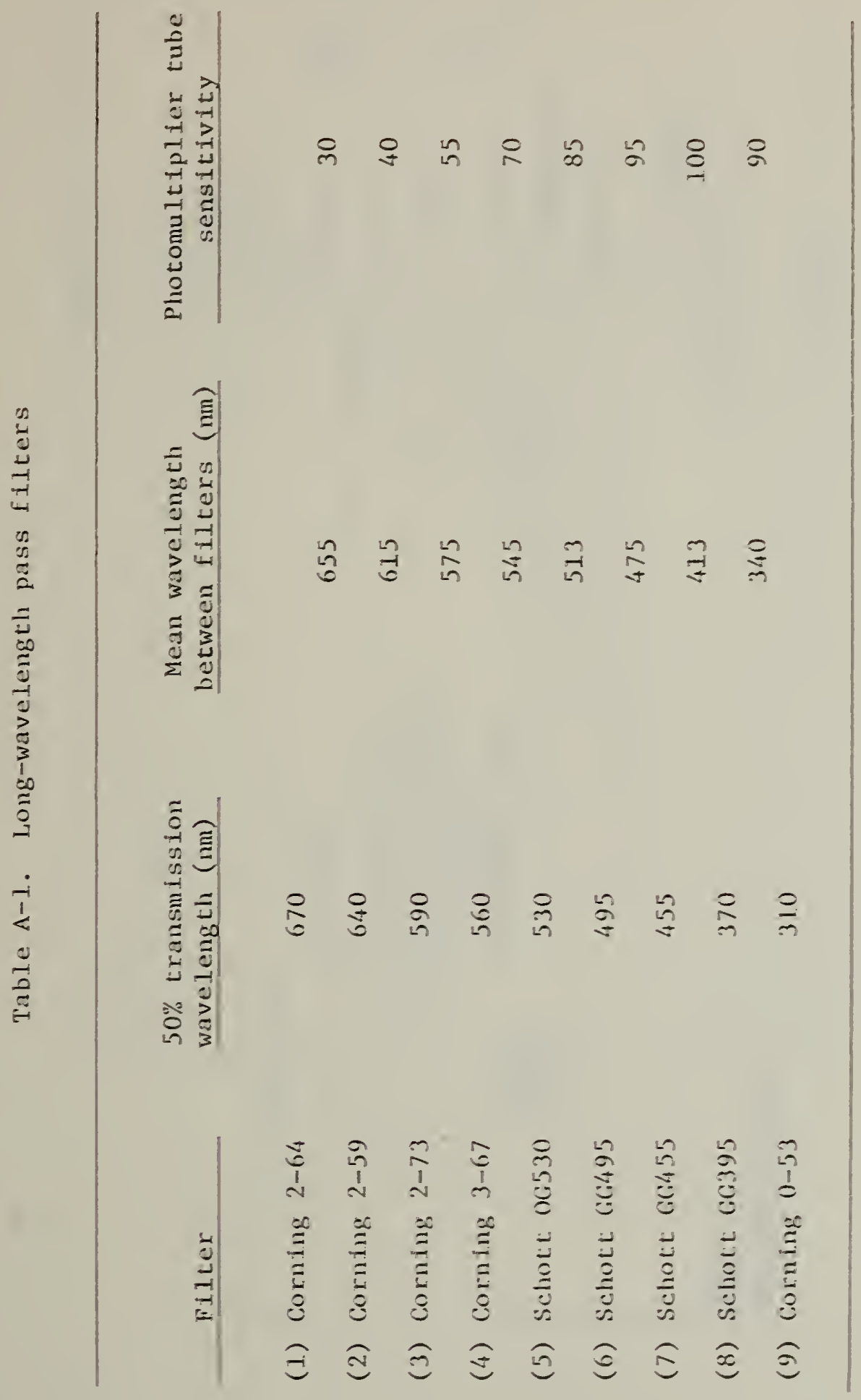




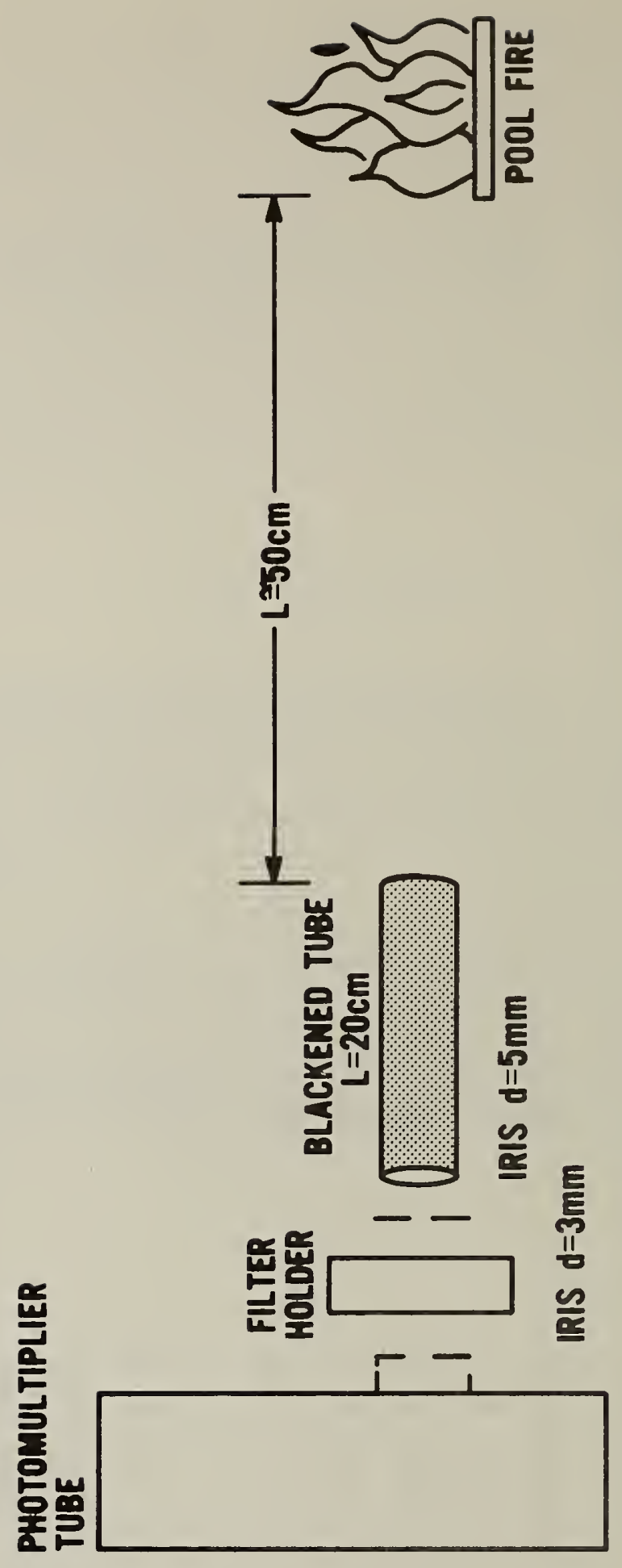




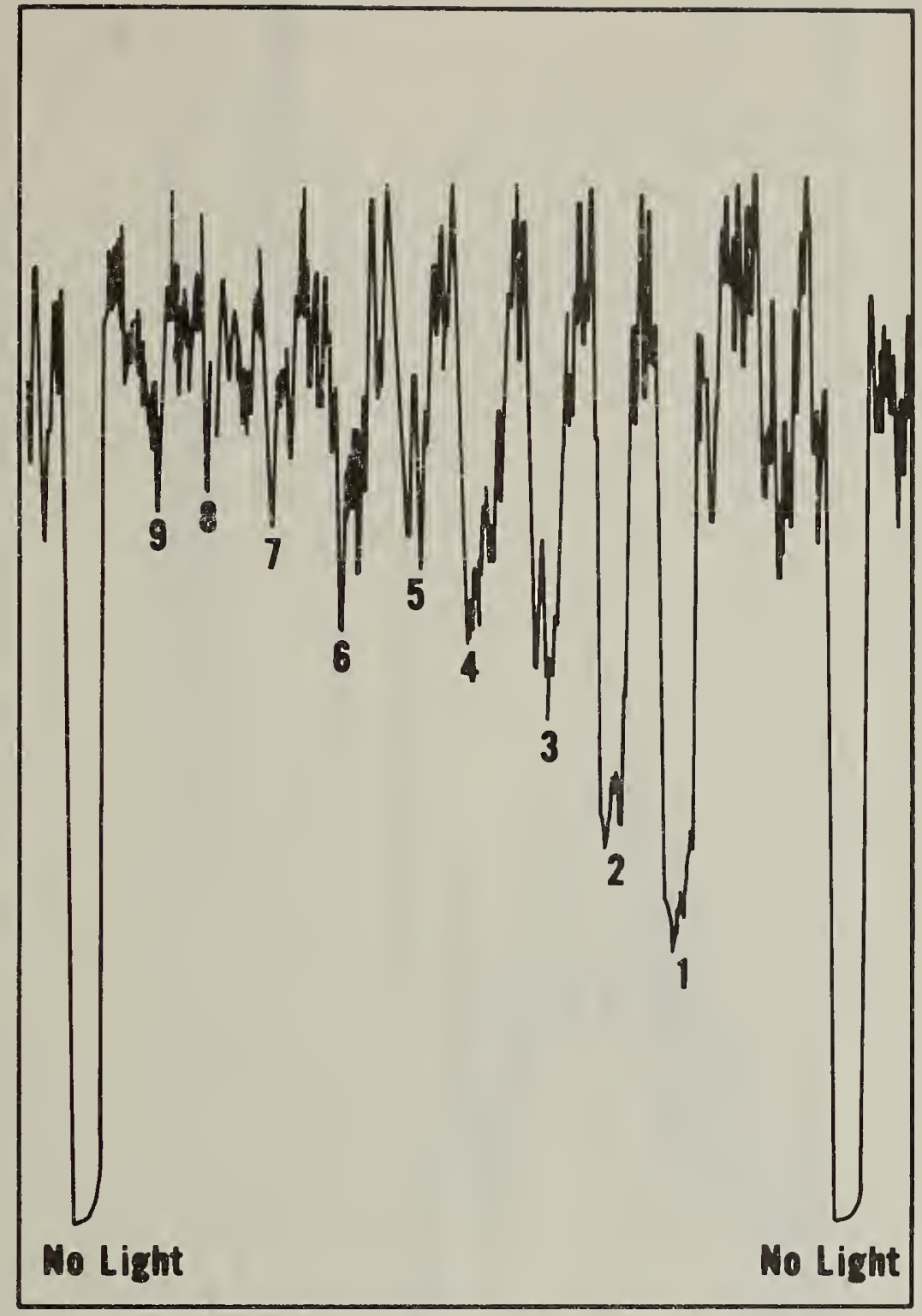

Figure A-2(a). Photomultiplier response data from pump oil fire (Numbers of inserted filters are indicated.) 


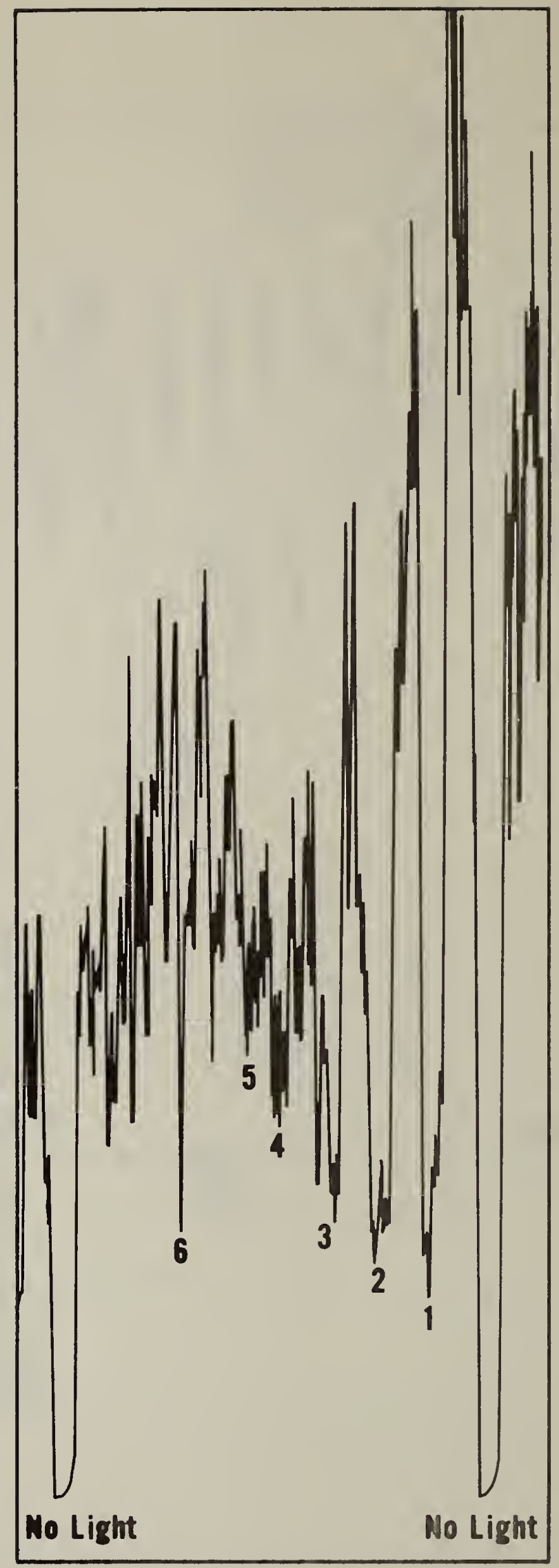

Figure A-2(b). Photomultiplier response data from silicone fluid fire (Numbers of inserted filters are indicated.) 


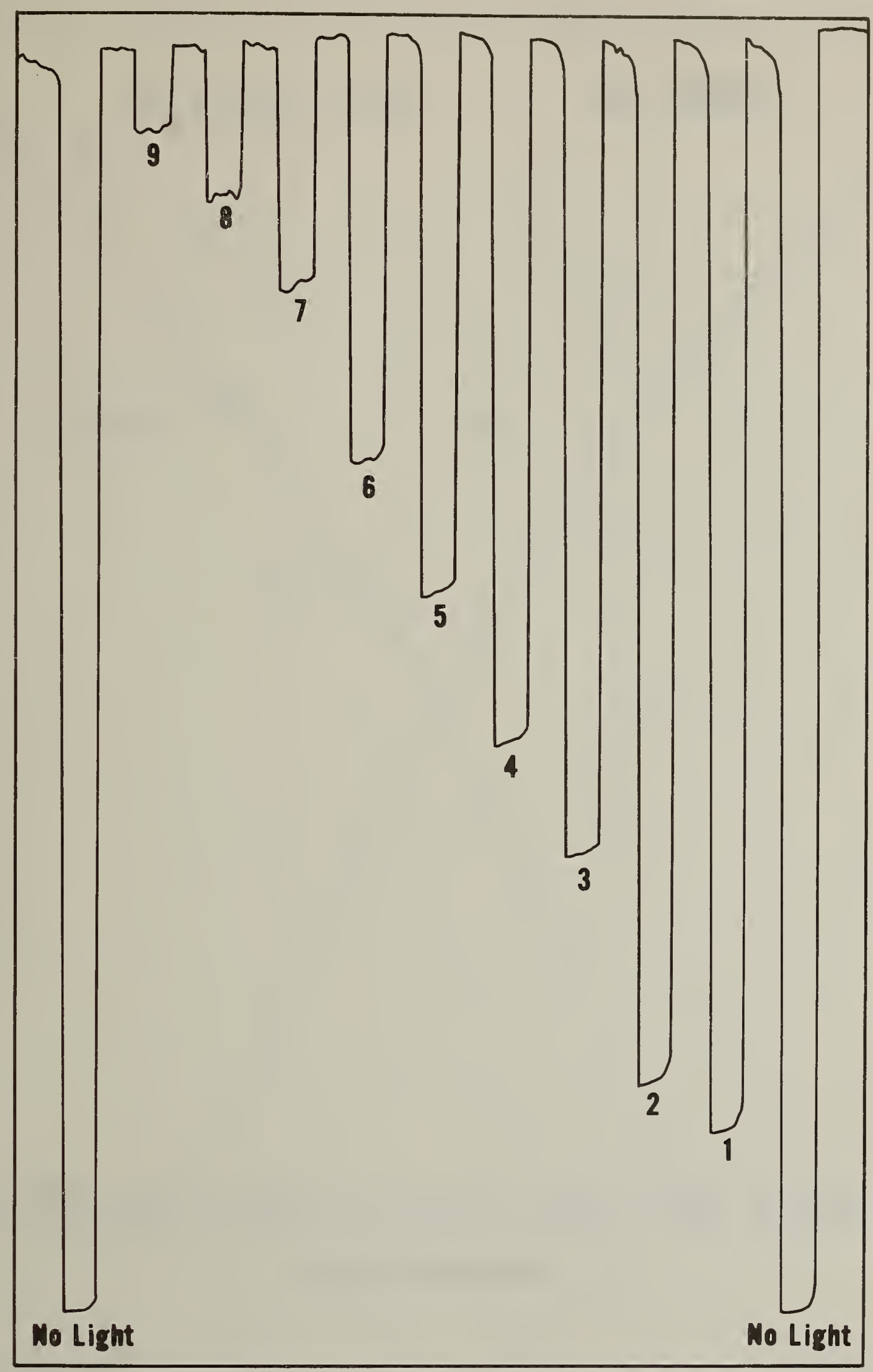

Figure A-2(c). Photomultiplier response data from tungsten bulb (Numbers of inserted filters are indicated.) 


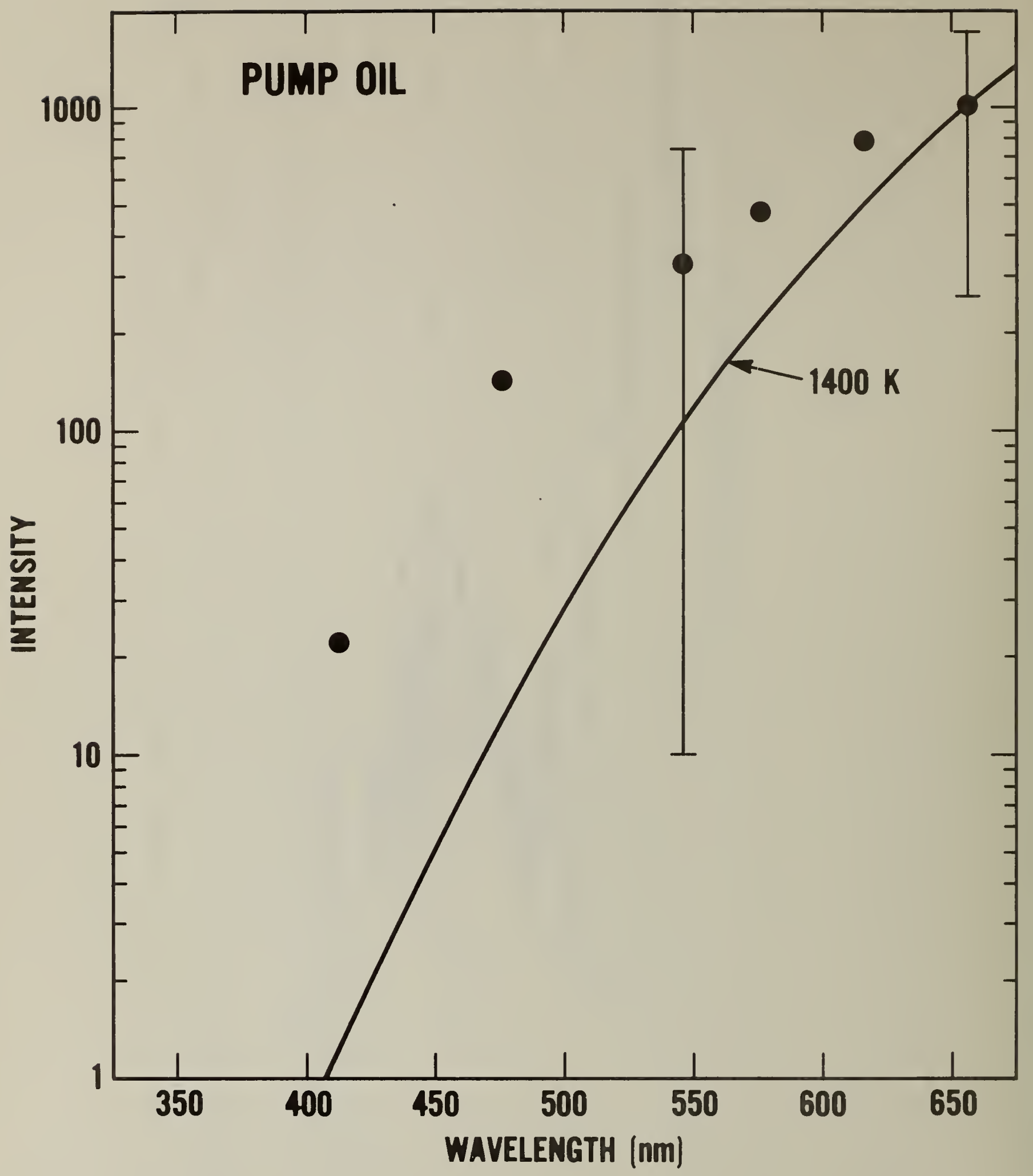

Figure A-3(a). Spectral data from pump oil fires (intensity in arbitrary units) The curve represents the blackbody emission at the optical pyrometer temperature. 


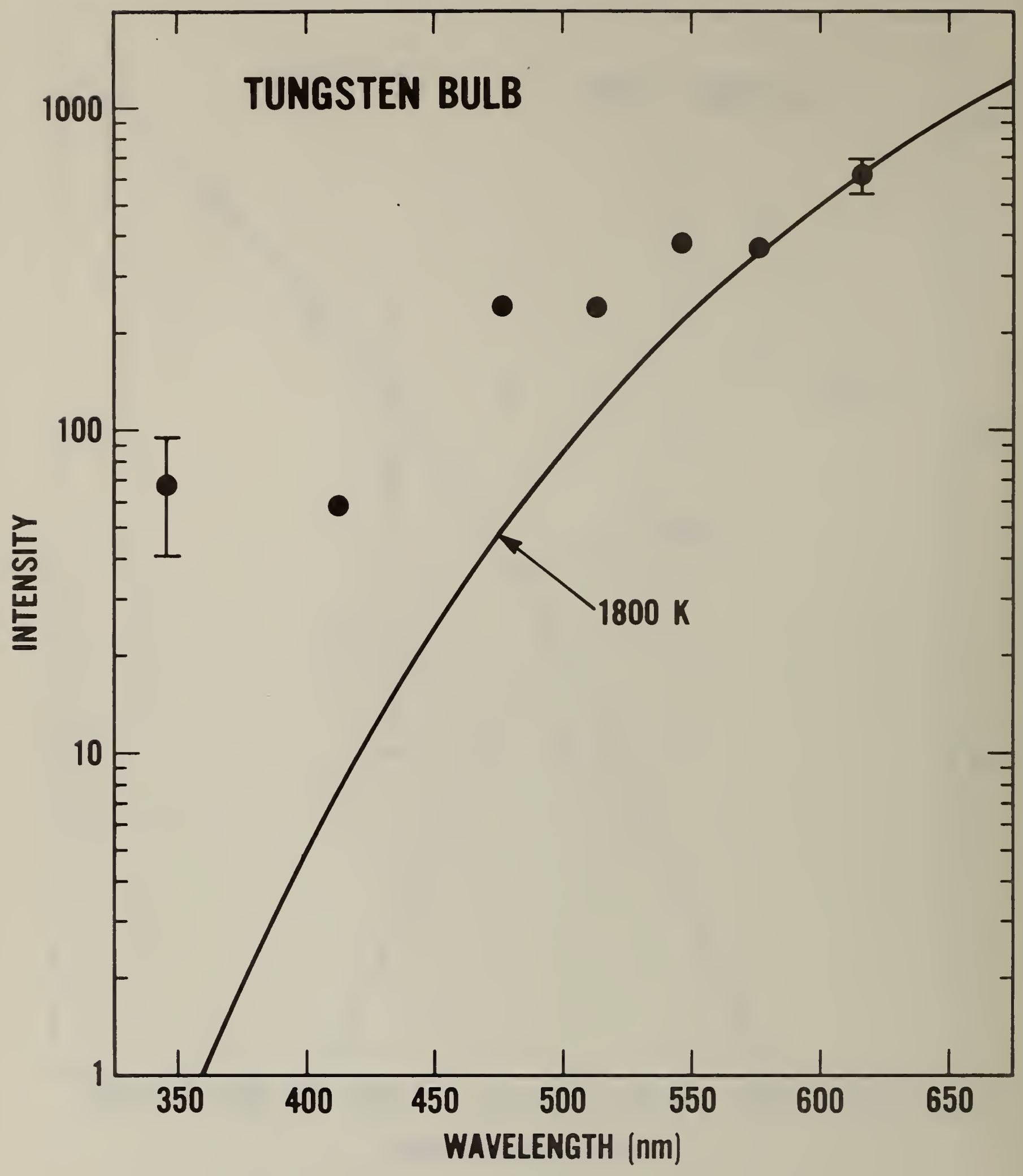

Figure $A-3(c)$. Spectral data from tungsten bulb fires (intensity in arbitrary units) The curve represents the blackbody emission at the optical pyrometer temperature. 


\section{Pollutant PCB Discovered In Food Products 'By Chance'}

\author{
By Joanne Omang \\ Washington Post staff writer
}

The spread of the chemical pollutant PCB to human and animal food in 17 states was' spotted "just by chanie" and could have gone unnoticed under curre nt government procedures, a Departinent of Agriculture cfficial said yesterday.

Assistant Secretary - Carol Tucker Foreman told a House hearing that bureaucratic routine and slipups accounted for the six-week delay between the taking of a food sample that proved to be PCB-loaded and the day that the Food and Drug Administration was notified of the contamination. But "even under the best of circumstances" it would have taken three to four weeks, she said.

The FDA is still tracking down ship. ments nationwide of cake mixes, waffle mixes and other products made with eggs that might have contained PCB from a Montana animal feed plant, according to acting FDA commissioner Sherwin Gardner. He said he was "reasonably certain" that none had escaped the FDA net but would not know for sure until all the reports are in and cerified in another 30 days.

PCB is polychlorinated biphenyl, a possibly cancer-causing chemical that has been linked to skin and liver disease, bone problems and other ail. ments. Banned in 1977, it previously was used as a lubricant and hightemperature coolant and fontinues to exist in older electrical transformers and industrial machinery.

It was such a transformer, apparently damaged by some kind of farm machinery or loading vehicle as it sat in a machine storage shed, that leaked about 200 gallons of oil containing $\mathrm{PCB}$ at the Pierce Packing $\mathrm{Co}$. of Billings, Mont., acçording; to the FDA.

The oll went into a drainage system that was routinely cleansed of fats for inclusion in animal feed. Foreman told the hearing that 399,000 pounds of affected poultry and 16,000 pounds of fresh pork have been located and held off the market. The FDA and USDA have alsc tracked the chemical to 73,000 pounds of egg products; about 52,000 pounds of which have been withheld. The rest is being - traced.

The Agriculture Department monitoring system spot checks animal carcasses and is designed to catch trends over a year-long period, Foreman said. "It was just by chance that we picked up this single incident relatively quickly," she added. "It is also possible that a single incident of this size could go entirely undetected."

She said there are 120 million head of livestock and 3.5 billion poultry marketed each year. "The cost of testing all of them for [dangerous chemical] residues would be about $\$ 100$ billion," she continued. Further, she said there are some dangerous chemicals, like the cancer-causing nitrofuranes, for which no residue-detecting test exists.

The PCB in this incident was found first in a chicken taken routinely from a processing plant in Provo, Utah, on July 6, Foreman related. But the USDA veterinarian who would have mailed the sample to be tested was on vacation and his replacement did not know a sample was waiting, so the mailing was delayed forta week.

On Aug. 3, the USDA iaspection office in Alameda, Calif, was told the sample contained $\mathrm{PCB}$, but waited until receiving written confirmation Aug. 8 before notifying the Utah office. That office traced the hen to the Pierce plant by the 10 th but did not notify the FDA until Aug. 16, six weeks from the day the sample was taken.

"We should have far more sensitiv" ity," Foreman said. "There should have been earlier and more compelling notification." She said corrective measures are being taken at the De partment of Agriculture, but warned, "We have to realize that as long as we use chemicals in agriculture .... accidents will occur."

Idaho Gov. John V. Evans objected in his testimony to "lapses ... slipshod procedures ... inexcusable delays" in government agency performance in the case. He recommended improved communication, technical and laboratory facilities and called for some sort of indemnification program for citizens damaged by future pollution problems.

"We've got to eliminate PCBs com. pletely," he said. But the subcommittee chairman, Rep. Bob Eckhardt (D. Tex.), said that would be "a massive and extremely difficult, costly thing." An Environmental Defense Fund witness, Jacqueline Warren, told the hearing there are still 275 million gallons of PCB oils in transformers in use.

'Rep. Andrew Maguire (D-N.J.) asked whether it would be possible to ban PCB at least in the nation's 125,000 food processing plants. Foreman and Gardner sald they thought that would be "feasible." 
NBS-114A (REV. 0-78)

\begin{tabular}{|c|c|c|c|}
\hline $\begin{array}{l}\text { U.S. DEPT. OF COMM. } \\
\text { BIBLIOGRAPHIC DATA } \\
\text { SHEET }\end{array}$ & $\begin{array}{l}\text { 1. PUBLICATION OR REPORT NO. } \\
\text { NBSIR } 80-1992\end{array}$ & 2. Gov't Accession No. & 3. Fecipnents Accession No? \\
\hline \multirow{2}{*}{\multicolumn{3}{|c|}{$\begin{array}{l}\text { DEVELOPMENT OF FLAMMABILITY CRITERIA } \\
\text { FOR TRANSFORMER DIELECTRIC FLUIDS }\end{array}$}} & $\begin{array}{l}\text { 5. Publication Date } \\
\text { February } 1980\end{array}$ \\
\hline & & & 6. Performing Organization Code \\
\hline \multicolumn{3}{|c|}{ Richard G. Gann } & 8. Performing Organ. Report No. \\
\hline \multicolumn{3}{|c|}{ 9. PERFORMING ORGANIZATION NAME AND ADDRESS } & 18. Project/Task/Nork Unit No. \\
\hline \multicolumn{3}{|c|}{$\begin{array}{l}\text { NATIONAL BUREAU OF STANDARDS } \\
\text { DEPARTMENT OF COMMERCE } \\
\text { WASHINGTON, DC } 20234\end{array}$} & 11. Contract/Grant No. \\
\hline \multirow{2}{*}{\multicolumn{3}{|c|}{$\begin{array}{l}\text { 12. SPONSORING ORGANIZATION NAME AND COMPLETE ADDRESS (Streot, City, Stato, zIP) } \\
\text { U.S. Department of Energy } \\
\text { Electric Energy Systems Division } \\
\text { Power Delivery Branch } \\
\text { Washington, D.C. } 20545\end{array}$}} & $\begin{array}{l}\text { 13. Type of Report \& Period Covered } \\
\text { Final }\end{array}$ \\
\hline & & & 14. Sponsoring Agency Code \\
\hline
\end{tabular}

15. SUPPLEMENTARY NOTES

Document describes a computer program; SF-185, FIPS Software Summary, is attached.

16. ABSTRACT (A 200-word or less factual summary of most significant information. If document includes a significant bibliography or literature survey, mention it here.)

With the recent ban on the use of polychlorinated biphenyls, it has become necessary to examine the fire safety requirements for electrical insulating fluids. The hazards are delineated and the magnitude of the transformer fire problem assessed. The current fire code and standard test methods are shown to be inadequate. Approaches to fluid fire performance testing are presented, as is a basis for evaluating the economic impact of alternative fire safety strategies. The report concludes with recommendations for further work.

17. KEY WORDS (six to twelve ontries; alphabetical order; capitalize only the first letter of the first koy word unleas a proper name oeparated by semicolons)

Fire; fluids; pool fires; transformers.

18. AVAILABILITY

For Official Distribution. Do Not Release to NTIS

Order From Sup. of Doc., U.S. Government Printing Office, Washington, DC 20402, SD Stock No. SNÖ03-003-

$\mathrm{X}$ Order From National Technical Information Service (NTIS), Springfield, VA. 22161

\begin{tabular}{|l|c|}
\hline $\begin{array}{l}\text { 19. SECURITY CLASS } \\
\text { (THIS REPORT) }\end{array}$ & $\begin{array}{c}\text { 21. NO. OF } \\
\text { PRINTED PAGES } \\
\text { UNCLASSIFIED }\end{array}$ \\
\hline $\begin{array}{l}\text { 20. SECURITY CLASS } \\
\text { (THIS PAGE) } \\
\text { UNCLASSIFIED }\end{array}$ & 22. Price \\
\hline 7.00 \\
\hline
\end{tabular}

